\title{
Genetic and phenotypic parameter estimates for body weights and egg production in Horro chicken of Ethiopia
}

\author{
Nigussie Dana $\cdot$ E. H. vander Waaij • \\ Johan A. M. van Arendonk
}

Accepted: 27 June 2010 /Published online: 14 July 2010

(C) The Author(s) 2010. This article is published with open access at Springerlink.com

\begin{abstract}
A breeding program has been established in 2008 to improve productivity of Horro chicken, an indigenous population in the western highlands of Ethiopia. The pedigree descended from 26 sires and 260 dams. Body weights were measured every 2 weeks from hatch to 8 weeks then every 4 weeks for the next 8 weeks. Egg production was recorded to 44 weeks of age for one generation. Genetic parameters were estimated using animal model fitted with common environmental effects for growth traits and ignoring common environment for egg production traits. Direct heritabilities ranged from low $(0.15 \pm 0.08)$, for body weight at 6 weeks, to moderate $(0.40 \pm 0.23)$, for hatch weight. Heritabilities of common environmental effects on growth were high at hatch $(0.39 \pm$ 0.10 ) and remained low afterwards. Age at first egg showed a very low heritability $(0.06 \pm 0.15)$. Heritabilities of egg numbers in the first, second, third, and fourth months of laying were $0.32( \pm 0.13), 0.20( \pm 0.16), 0.56( \pm 0.15)$, and $0.25( \pm 0.14)$, respectively. Heritabilities of cumulative of monthly records of egg numbers were from $0.24 \pm 0.16$ (for the first 2 months, EP12) to $0.35 \pm 0.16$ (over the 6 months, EP16). Body weight at 16 weeks of age (BW16) has a strong genetic correlation with the cumulative of monthly records: 0.92 (with EP12), 0.69 (with EP36), and 0.73 (with
\end{abstract}

N. Dana $(\bowtie)$

Ethiopian Institute of Agricultural Research,

P.O. Box 32, Debre Zeit, Ethiopia

e-mail: negussiedana@yahoo.com

N. Dana $\cdot$ J. A. M. van Arendonk

Animal Breeding and Genomics Centre, Wageningen University,

P.O. Box 338, 6700 AH Wageningen, The Netherlands

E. H. vander Waaij

Adaptation Physiology Group, Wageningen University,

P.O. Box 338, 6700 AH Wageningen, The Netherlands
EP16). Besides their strong association, BW16 and EP16 showed higher heritability, relative to their respective trait categories. These two traits seemed to have common genes and utilizing them as selection traits would be expected to improve both egg production and growth performance of local chicken. However, the standard errors of estimates in this study were mostly high indicating that the estimates have low precision. Parameter estimations based on more data are needed before applying the current results in breeding programs.

Keywords Indigenous chicken - Growth - Egg production · Heritability · Correlations

\section{Introduction}

Indigenous chickens comprise about $80 \%$ of the national flocks in Africa and Asia. Compared to their modern counterparts indigenous chickens are generally poor producers of eggs and meat. Consequently, they are being replaced by commercial strains in many developing countries. In some countries this strategy was pursued for decades to increase productivity under village systems but failed to bring sustainable improvement (Teklewold et al. 2006). In fact, it posed a serious threat to the existing genetic diversity of indigenous chickens (Besbes 2009).

Despite their low growth rates and egg production, indigenous chickens are generally better in disease resistance and could maintain higher level of performance under poor nutrition and high environmental temperatures compared to commercial strains under village systems (Horst 1989). This is clear evidence of the positive attributes of indigenous chickens. Studies on biodiversity of indigenous chickens in many parts of Africa revealed the presence of high genetic 
variability within ecotype populations (Muchadeyi et al. 2007; Mwacharo et al. 2007; Halima et al. 2009) indicating the potential for genetic improvement of these chickens through selective breeding. The present work is based on a selection scheme initiated in 2008 to improve growth and egg production of Horro chickens.

Horro is an indigenous chicken type named after the geographic region of origin located in the western part of Ethiopia near the Blue Nile gorge. There are about 30,000 chickens restricted to this original environment (Dana et al. 2010). The population has a wide range of morphologic and genetic diversity. The program aims to make Horro chickens more profitable for the poor people in these regions and conserve the existing genetic diversity. If this program is successful then it will be used as a benchmark for improving other indigenous chicken genetic resources.

Knowledge on genetic parameters is essential for any genetic improvement program. There is a lot of literature on genetic parameters for growth and egg production of

Table 1 Means of body weights ${ }^{\mathrm{a}}$ of Horro chicken by sex and for both sexes combined

\begin{tabular}{|c|c|c|}
\hline & $n^{\mathrm{b}}$ & Mean, g $( \pm$ SE $)$ \\
\hline \multicolumn{3}{|l|}{ Male } \\
\hline BW0 & 642 & $24.9(0.13)$ \\
\hline BW2 & 642 & $59.6(0.46)$ \\
\hline BW4 & 641 & $113.9(1.10)$ \\
\hline BW6 & 640 & $181.6(1.58)$ \\
\hline BW8 & 606 & $277.8(2.60)$ \\
\hline BW12 & 528 & $485.5(5.97)$ \\
\hline BW16 & 388 & $701.1(12.13)$ \\
\hline \multicolumn{3}{|l|}{ Female } \\
\hline BW0 & 872 & $24.6(0.10)$ \\
\hline BW2 & 871 & $52.2(0.37)$ \\
\hline BW4 & 871 & $93.4(0.87)$ \\
\hline BW6 & 870 & $146.0(1.31)$ \\
\hline BW8 & 849 & $216.0(2.19)$ \\
\hline BW12 & 764 & $388.3(4.51)$ \\
\hline BW16 & 646 & $572.7(7.27)$ \\
\hline \multicolumn{3}{|c|}{ Both sexes combined } \\
\hline BW0 & 1,514 & $24.7(0.08)$ \\
\hline BW2 & 1,513 & $55.4(0.30)$ \\
\hline BW4 & 1,512 & $102.1(0.73)$ \\
\hline BW6 & 1,510 & $161.1(1.10)$ \\
\hline BW8 & 1,455 & $241.8(1.86)$ \\
\hline BW12 & 1,292 & $428.0(3.85)$ \\
\hline BW16 & 1,034 & $620.9(6.71)$ \\
\hline
\end{tabular}

${ }^{\mathrm{a} B W 0}$, hatch weight; BW2, BW4, BW6, BW8, BW12, and BW16, body weights at $2,4,6,8,12$, and 16 weeks of age, respectively

${ }^{\mathrm{b}}$ Number of animals commercial poultry populations (see reviews by Chambers 1990; Fairful and Gowe 1990); however, these values may not be applicable to these indigenous chickens. There are some estimates for growth (Norris and Ngambi 2006; Gondwe 2005) and egg production (Francesch et al. 1997; Sang et al. 2006; Kamali et al. 2007; Lwelamira et al. 2009) traits in unselected indigenous chickens of Africa and other countries but there are no estimates for Ethiopian chickens.

The aim of this study was to estimate heritabilities and genetic and phenotypic correlations for growth and egg production traits to understand which traits should be included in breeding programs for Horro chickens.

\section{Materials and methods}

Experimental population and traits measured

The study was done at the Ethiopian Institute of Agricultural Research, Debre Zeit Agricultural Research Center (DZARC). The population was established from 3,000 eggs purchased from two village market sheds in Horro. The pedigree descended from 26 sires and 260 dams and were hatched and raised at the poultry research farm of DZARC. The offspring were hatched in three batches between January and February 2008. Birds in all age classes were provided ad libitum access to feed and water. Starting chick feed $(20 \% \mathrm{CP}$ and 2,950-3,000 kcal $/ \mathrm{kg}$ ) for the first 3 weeks and grower ration $(18 \% \mathrm{CP}$ and $2,850-2,900 \mathrm{kcal} / \mathrm{kg}$ ) from 3 to 10 weeks. Between 10 and 16, 16 and 18, and from 18 weeks onward the birds were provided with pullet ration $(16 \% \mathrm{CP}$ and 2,700 $2,750 \mathrm{kcal} / \mathrm{kg})$, pullet/layer blend and layer ration $(17-18 \% \mathrm{CP}$ and $2,700-2,750 \mathrm{kcal} / \mathrm{kg}$ ), respectively. The chickens were reared in a single deep litter house until 18 weeks of age under a standard housing space, with natural lightning after 8 weeks of age. After 18 weeks of age a total of 240 females and 24 males were picked randomly and transferred to layer houses and reared in floor cages with one male and 10 females in each pen. Each pen had a trap nest for individual recording of egg production and pedigree. The remaining animals were sold due to limitations in housing space. All chickens were vaccinated against Newcastle and Marek's diseases at 1 day old, Gumboro at 1 week, and fowl pox at 10 weeks.

Live weight growth was measured every 2 weeks for the first 8 weeks then every 4 weeks for the next 8 weeks. Traits recorded were: body weights at hatch (BW0) and body weights in weeks 2 (BW2), 6 (BW6), 8 (BW8), 12 (BW12), and 16 (BW16). Age at first egg (AFE) was recorded for each hen. Early part egg production record, defined as the number of eggs produced from housing to about 44 weeks of age, was used to study egg production traits. Egg production was recorded for six 4-week periods: 21 to 24,25 to 28,29 to 32,33 to 36,37 to 40 , and 41 to 
Table 2 Mean monthly ${ }^{\mathrm{a}}$ and cumulative ${ }^{\mathrm{b}}$ number of eggs, hen-day (HDP) and hen-housed (HHP) rates of egg production and mortality during the early part laying period, to 44 weeks of age, in Horro chicken

\begin{tabular}{|c|c|c|c|c|c|c|}
\hline Trait & Period (week) & Hens housed, $n$ & Mean, $n( \pm \mathrm{SE})$ & HDP $(\%)$ & HHP (\%) & Mortality (\%) \\
\hline M1 & $21-24$ & 328 & $0.71(0.13)$ & 2.53 & 2.34 & 7.6 \\
\hline M2 & $25-28$ & 303 & $4.06(0.33)$ & 14.50 & 12.87 & 11.2 \\
\hline M3 & $29-32$ & 269 & $7.82(0.41)$ & 27.93 & 26.69 & 4.5 \\
\hline M4 & $33-36$ & 257 & $8.98(0.44)$ & 32.07 & 30.82 & 4.0 \\
\hline M5 & $37-40$ & 247 & $8.25(0.44)$ & 29.47 & 28.51 & 3.2 \\
\hline M6 & $41-44$ & 239 & $7.34(0.39)$ & 26.23 & 25.57 & 2.5 \\
\hline EP12 & $21-28$ & 328 & $4.78(0.41)$ & 8.68 & 7.12 & 18.0 \\
\hline EP36 & $29-44$ & 269 & 31.77 (1.31) & 30.31 & 26.26 & 13.4 \\
\hline EP16 & $21-44$ & 328 & 33.64 (1.56) & 23.55 & 16.73 & 29.0 \\
\hline AFE & & 203 & $190.00(1.77)$ & & & \\
\hline
\end{tabular}

$A F E$ age at first egg (in days)

${ }^{a}$ M1, M2, M3, M4, M5, and M6, egg numbers in the first, second, third, fourth, fifth, and sixth months, respectively

${ }^{\mathrm{b}} \mathrm{EP} 12$, EP36, and EP16, cumulative number of eggs produced from months 1 to 2, 3 to 6 , and 1 to 6 , respectively

44 weeks of age. Each of these 4-week intervals comprised the monthly records of egg numbers: M1, M2, M3, M4, M5, and M6, respectively. The cumulative of monthly egg production records were used for analyzing part period production. The number of eggs produced in periods 1 (EP12), 2 (EP36), and 3 (EP16) were the cumulative number of eggs produced from months 1 to 2, 3 to 6 and 1 to 6 , respectively. Box-Cox transformation was used to achieve normality in egg production data (Besbes et al. 1993).

\section{Statistical analyses}

Descriptive statistics of growth and egg production data were carried out in the SAS package (Statistical Analysis System SAS 2001) using all available records. Only records from hens which survived to 44 weeks of age were included in the genetic analysis of egg traits. Parameter estimates for both growth and egg traits were obtained by univariate animal model using ASREML (Gilmour et al.
2006). Heritabilities of growth traits were estimated including a common environment effect. The following linear model was used:

$\mathbf{Y}=\mathbf{X b}+\mathbf{Z a}+\mathbf{Z c}+\mathrm{e}$

Where, $\mathbf{Y}=$ vector of observations; $\mathbf{b}=$ vector of fixed effects of sex and hatch number; $\mathbf{a}=$ vector of random direct genetic effects; $\mathbf{c}=$ vector of random common environmental effects; $\mathbf{e}=$ vector of residual effects; and $\mathbf{X}, \mathbf{Z a}$, and $\mathbf{Z c}$ are incidence matrices relating records to fixed, direct genetic, and common environmental effects, respectively. Maternal genetic effects could not be estimated due to the small data size. The common environmental effect did not exist for body weights in weeks 12 and 16 and was, thus, excluded from the model. A similar procedure was used for analyzing egg production traits but ignoring common environment from the model and using hatch number, house, and pen as the fixed effects. Correlations were estimated using a bivariate analysis. Because convergence could not be achieved when the common environmental effect was
Fig. 1 Frequency distribution of the number of eggs produced by hens that survived throughout the recording period (44 weeks of age)

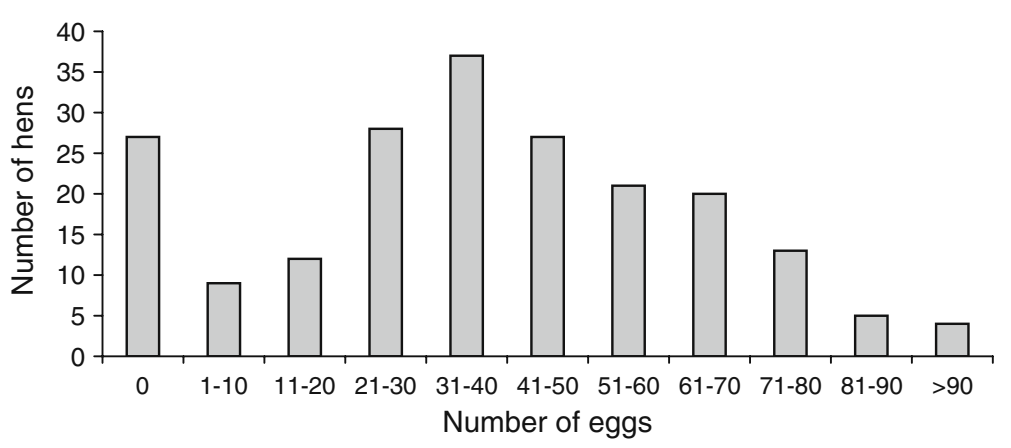




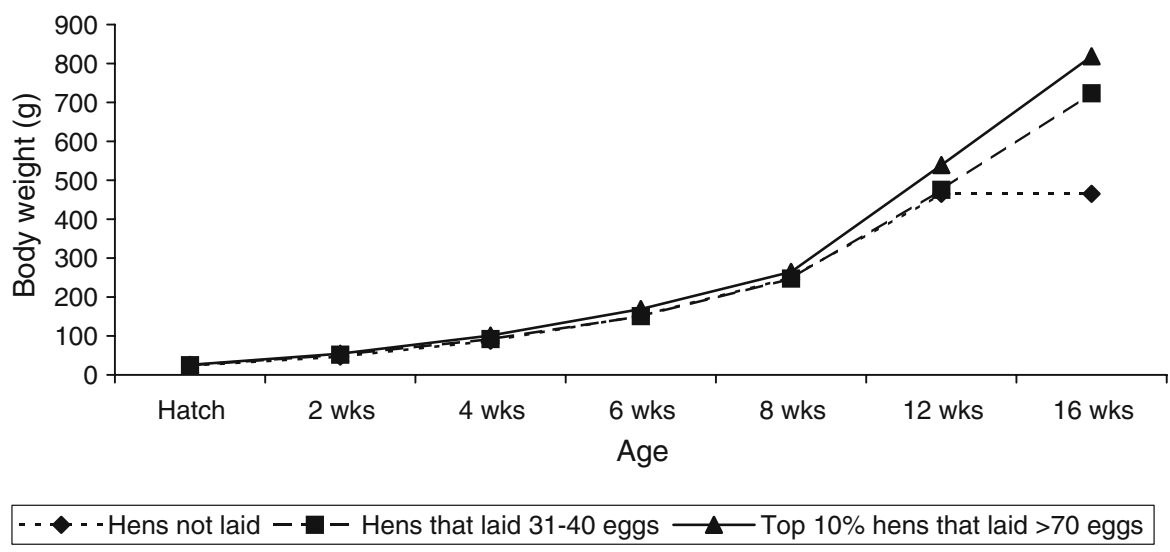

Fig. 2 The trends in growth performance of hens to 16 weeks in relation to their total egg production at 44 weeks of age

included in the model, correlations were estimated with animal as the only random effect.

\section{Results}

\section{Basic statistics}

Table 1 shows means of body weights for Horro chicken to 16 weeks of age. Means of body weights from hatch to 16 weeks of age ranged from 25 to $701 \mathrm{~g}$ in males and from 25 to $573 \mathrm{~g}$ in females. Overall, the mean hatch weight of Horro chicken was about $25 \mathrm{~g}$ which increased to $621 \mathrm{~g}$ at 16 weeks of age.

The average number of eggs produced monthly and cumulative of part records for the laying period were shown in Table 2. Hens attained sexual maturity at an average of 190 days. About $16 \%$ of the hens started laying between 21 and 24 weeks of age. Most of the hens housed did not lay during this period and only started laying after 25 weeks of age. Mean monthly egg numbers ranged from 0.7 at the beginning of laying to 9 in the fourth month. Peak egg production was achieved at the fourth month of laying which started to drop in the following months. Averages of cumulative of monthly records in the first 2 months (EP12), from month 3 to 6 (EP36) and the total over 6 months (EP16) were around 5, 32, and 34, respectively. Hen-day rate of egg production, defined as the number of egg produced by the hens housed divided by the product of the number of days in production and the number of hens alive, increased from $2.5 \%$ in the first month to $32 \%$ in the fourth month of laying and declined afterwards. Mortality in the laying house increased from $8 \%$ in the first month (21-24 weeks) to $11 \%$ in the second month but steadily decreased and remained low in the following periods. The total rate of mortality during the laying period was $29 \%$, slightly lower compared to the total mortality from hatch to 16 weeks of age (32\%) most of which occurred after 6 weeks of age (see Table 1 for the number of animals that survived at different ages).

Figure 1 shows the distribution of the number of eggs produced in relation to the number of hens that survived to 44 weeks of age. More than $13 \%$ of the hens did not lay at all throughout this period. Relatively, the largest proportion of hens (37 of 203,18.2\%) laid between 31 and 40 eggs. The top $10 \%$ hens produced between 71 and a little more than 90 eggs. However, the proportion of hens that laid

Table 3 Variance components ${ }^{\mathrm{a}}$ and heritabilities ${ }^{\mathrm{b}}$ of body weights ${ }^{\mathrm{c}}$ in Horro chickens (for hens survived to 44 weeks of age)

\begin{tabular}{lccccrrrrr}
\hline Trait & Animals, $n$ & Records, $n$ & Sires, $n$ & Dams, $n$ & $\sigma_{\mathrm{a}}{ }^{2}$ & $\sigma_{\mathrm{c}}{ }^{2}$ & $\sigma^{2} \mathrm{e}$ & $\mathrm{h}^{2}( \pm \mathrm{SE})$ & $\mathrm{c}^{2}( \pm \mathrm{SE})$ \\
\hline BW0 & 1,456 & 1,307 & 25 & 143 & 3.9 & 3.7 & 2.0 & $0.40(0.23)$ & $0.39(0.10)$ \\
BW2 & 1,434 & 1,306 & 25 & 142 & 19.1 & 11.4 & 71.7 & $0.19(0.11)$ & $0.11(0.05)$ \\
BW6 & 1,330 & 1,303 & 25 & 141 & 197.4 & 43.8 & $1,073.3$ & $0.15(0.08)$ & $0.03(0.03)$ \\
BW8 & 1,262 & 1,248 & 25 & 138 & 516.9 & 36.6 & $2,643.2$ & $0.16(0.08)$ & $0.01(0.03)$ \\
BW12 & 1,092 & 1,090 & 25 & 136 & $2,399.0$ & & $12,410.0$ & $0.16(0.05)$ & - \\
BW16 & 845 & 845 & 25 & 132 & $9,673.0$ & & $33,220.0$ & $0.23(0.06)$ & - \\
\hline
\end{tabular}

${ }^{\mathrm{a}} \sigma_{\mathrm{a}}{ }^{2}, \sigma_{\mathrm{c}}{ }^{2}$, and $\sigma^{2} \mathrm{e}$, additive genetic, common environmental, and residual variances, respectively

${ }^{\mathrm{b}} \mathrm{h}^{2}$ and $\mathrm{c}^{2}$, heritabilities of direct genetic and common environmental effects, respectively

${ }^{\mathrm{c}}$ BW0, hatch weight; BW2, BW6, BW8, BW12, BW16, body weights at 2, 6, 8, 12, and 16 weeks of age, respectively 
Table 4 Variance components ${ }^{\mathrm{a}}$ and heritabilities ${ }^{\mathrm{b}}$ of monthly ${ }^{\mathrm{c}}$ and cumulative ${ }^{\mathrm{d}}$ egg numbers during early part laying period in Horro chickens (for hens survived to 44 weeks of age)

\begin{tabular}{lcccccrrr}
\hline Trait & Period (weeks) & Animals, $n$ & Records, $n$ & Sires, $n$ & Dams, $n$ & $\sigma_{\mathrm{a}}^{2}$ & $\sigma^{2} \mathrm{e}$ & $\mathrm{h}^{2}( \pm \mathrm{SE})$ \\
\hline M1 & $21-24$ & 203 & 176 & 23 & 69 & 0.1 & 0.2 & $0.32(0.13)$ \\
M2 & $25-28$ & 203 & 176 & 23 & 69 & 2.6 & 10.2 \\
M3 & $29-32$ & 203 & 176 & 23 & 69 & $0.20(0.16)$ \\
M4 & $33-36$ & 203 & 176 & 23 & 69 & 15.5 & 12.2 & $0.56(0.15)$ \\
EP12 & $21-28$ & 203 & 176 & 23 & 69 & 6.1 & 21.8 & $0.25(0.14)$ \\
EP36 & $29-44$ & 203 & 176 & 23 & 69 & 67.6 & 174.9 & $0.24(0.16)$ \\
EP16 & $21-44$ & 203 & 176 & 23 & 69 & 115.9 & 216.5 & $0.28(0.15)$ \\
AFE & & 203 & 176 & 23 & 69 & 31.5 & 458.5 & $0.06(0.16)$ \\
\hline
\end{tabular}

$A F E$ age at first egg (in days)

${ }^{\mathrm{a}} \sigma_{\mathrm{a}}{ }^{2}, \sigma_{\mathrm{c}}{ }^{2}$, and $\sigma^{2} \mathrm{e}$, additive genetic, common environmental, and residual variances, respectively

${ }^{\mathrm{b}} \mathrm{h}^{2}$, heritability of direct genetic and common environmental effects, respectively

${ }^{\mathrm{c}} \mathrm{M} 1, \mathrm{M} 2$, M3, and M4, egg numbers in the first, second, third, and fourth months, respectively

${ }^{\mathrm{d}}$ EP12, EP36, and EP16, cumulative number of eggs produced from months 1 to 2,3 to 6 , and 1 to 6 , respectively

more than 80 eggs was less than $5 \%$. The associations between the phenotypic performance of body weight growth and total egg production at 44 weeks of age were shown in Fig. 2. The top $10 \%$ of hens with superior egg production had higher body weight at 16 weeks of age compared both to the hens that laid from 31 to 40 eggs and non-layers. On average the body weight of non-layers remained unchanged from 12 to 16 weeks of age.

Heritabilities of growth and egg production

Tables 3 and 4 present the variance components and heritabilities for growth and egg production traits. Estimates on additive genetic variances for growth traits ranged from 3.9 for body weight at hatch to 9,673 for body weight at
16 weeks of age. Environmental variances also showed similar trends, generally increasing from hatch to 16 weeks of age. Common environmental variances were observed for body weights at hatch and those at weeks 2,6 , and 8 while they were not detected for body weights in weeks 12 and 16 due to lack of convergence.

Estimates of direct heritability of growth traits ranged from 0.15 (BW6) to 0.40 (BW0). The values were moderate for body weight at 16 weeks of age (0.23) and that of hatch weight but remained low for the rest of the traits. Common environmental effect was moderate for hatch weight (0.39) but almost nonexistent for the remaining traits. Age at first egg showed a very low heritability (0.06). Heritabilities of monthly egg numbers ranged from 0.20 to 0.32 , except for M3 for which heritability was 0.56 . Heritabilities of

Table 5 Genetic (below diagonal) and phenotypic (above diagonal) correlations between body weights ${ }^{\mathrm{a}}$ and cumulative early part period egg numbers ${ }^{\mathrm{b}}$

\begin{tabular}{llllllllll}
\hline Trait & BW0 & BW2 & BW6 & BW8 & BW12 & BW16 & EP12 & EP36 & EP16 \\
\hline BW0 & & $0.45(0.03)$ & $0.22(0.03)$ & $0.15(0.03)$ & $0.09(0.03)$ & $0.10(0.03)$ & $0.06(0.08)$ & $0.19(0.07)$ & $0.19(0.08)$ \\
BW2 & $0.71(0.08)$ & & $0.64(0.02)$ & $0.53(0.02)$ & $0.37(0.03)$ & $0.27(0.03)$ & $0.16(0.07)$ & $0.07(0.08)$ & $0.13(0.08)$ \\
BW6 & $0.46(0.10)$ & $0.85(0.06)$ & & $0.85(0.01)$ & $0.59(0.01)$ & $0.40(0.03)$ & $0.25(0.07)$ & $0.16(0.07)$ & $0.21(0.07)$ \\
BW8 & $0.37(0.11)$ & $0.77(0.08)$ & $0.97(0.02)$ & & $0.74(0.01)$ & $0.56(0.02)$ & $0.19(0.07)$ & $0.11(0.08)$ & $0.15(0.07)$ \\
BW12 & $0.25(0.13)$ & $0.54(0.13)$ & $0.68(0.11)$ & $0.86(0.06)$ & & $0.82(0.01)$ & - & - & - \\
BW16 & $0.30(0.12)$ & $0.51(0.13)$ & $0.67(0.12)$ & $0.82(0.08)$ & $0.99(0.03)$ & & $0.35(0.07)$ & $0.31(0.07)$ & $0.38(0.06)$ \\
EP12 & $0.30(0.38)$ & $0.22(0.48)$ & $-0.54(0.93)$ & - & - & $0.92(0.35)$ & & $0.39(0.06)$ & $0.59(0.05)$ \\
EP36 & $0.40(0.36)$ & $-0.16(0.56)$ & - & - & - & $0.69(0.43)$ & $0.80(0.32)$ & \\
EP16 & $0.42(0.31)$ & $0.02(0.46)$ & - & $0.15(0.07)$ & - & $0.73(0.32)$ & $0.88(0.21)$ & $0.98(0.02)$ & $0.96(0.01)$ \\
\hline
\end{tabular}

${ }^{\mathrm{a}} \mathrm{BW} 0$, hatch weight; BW2, BW6, BW8, BW12, and BW16, body weights at weeks 2, 6, 8, 12, and 16, respectively

${ }^{\mathrm{b}}$ EP12, EP36, and EP16, cumulative number of eggs produced from months 1 to 2, 3 to 6, and 1 to 6, respectively 
Table 6 Genetic (below diagonal) and phenotypic (above diagonal) correlations between monthly ${ }^{\mathrm{a}}$ and cumulative ${ }^{\mathrm{b}}$ number of eggs produced during the early part laying period

\begin{tabular}{|c|c|c|c|c|c|c|c|}
\hline Trait & M1 & M2 & M3 & M4 & Ep12 & Ep36 & Ep16 \\
\hline M1 & & $0.38(0.06)$ & $0.10(0.07)$ & $0.18(0.07)$ & $0.48(0.05)$ & $0.22(0.07)$ & $0.38(0.06)$ \\
\hline M2 & - & & $0.40(0.06)$ & $0.16(0.07)$ & - & $0.39(0.06)$ & $0.59(0.04)$ \\
\hline M3 & $0.29(0.37)$ & $0.94(0.32)$ & & $0.25(0.07)$ & $0.39(0.06)$ & $0.58(0.04)$ & $0.59(0.04)$ \\
\hline M4 & $-0.15(0.47)$ & $0.71(0.52)$ & $0.97(0.39)$ & & $0.16(0.07)$ & $0.73(0.03)$ & $0.68(0.04)$ \\
\hline EP12 & - & - & $0.83(0.26)$ & $0.46(0.45)$ & & $0.39(0.06)$ & $0.59(0.05)$ \\
\hline EP36 & $0.16(0.46)$ & - & - & $0.81(0.19)$ & $0.80(0.32)$ & & $0.96(0.01)$ \\
\hline EP16 & $0.38(0.37)$ & - & - & $0.74(0.21)$ & $0.88(0.21)$ & $0.98(0.02)$ & \\
\hline
\end{tabular}

${ }^{\mathrm{a}} \mathrm{M} 1, \mathrm{M} 2, \mathrm{M} 3$, and M4, egg numbers in the first, second, third, and fourth months, respectively

${ }^{\mathrm{b}}$ EP12, EP36, and EP16, cumulative number of eggs produced from months 1 to 2, 3 to 6 , and 1 to 6 , respectively

cumulative part record egg numbers were from 0.24 (EP12) to 0.35 (EP16).

Correlations within and among growth and egg production traits

Table 5 shows the relationships within and among body weights and cumulative number of eggs produced between 1 and 2 (EP12), 3 and 6 (EP36), and 1 and 6 (EP16) months of laying. The correlations between hatch weight and most other traits were generally low. Among other growth traits, genetic correlations ranged from 0.51 (BW2 with BW16) to 0.99 (BW12 with BW16) and phenotypic correlations from 0.27 (BW2 with BW16) to 0.85 (BW6 with BW8). Genetic correlations among part record egg numbers ranged from 0.79 (EP12 with EP36) to 0.98 (EP36 with EP16).

The correlations between body weights and part record egg numbers did not converge for growth traits in weeks 6 , 8 , and 12 with egg traits. Correlations of the egg traits with body weight at hatch and weight in week 2 were generally low (Table 5). Interesting genetic correlations were observed for body weight at 16 weeks with part record egg numbers. Body weight at this age was strongly and positively correlated with EP12 (0.92), EP36 (0.69), and EP16 (0.73). Negative genetic correlation existed between BW6 and EP12 (-0.54). The phenotypic correlations between body weight and part record egg numbers generally appeared to be low, ranging from 0.06 (BW0 with EP12) to 0.38 (BW16 with EP16). However, the standard errors of all estimates between growth and egg production traits were quite high reflecting the small sample size. Table 6 presents the correlations between monthly and cumulative part record egg numbers. The highest correlations were found between the number of eggs recorded in the third month (M3) and cumulative part record of the first 2 months (EP12) $\left(r_{\mathrm{g}}=0.83\right.$, $\left.r_{\mathrm{p}}=0.39\right)$ while the other part records, EP36 and EP16, were strongly correlated with $\mathrm{M} 4\left(r_{\mathrm{g}}=0.74\right.$ to $0.81, r_{\mathrm{p}}=0.68$ to 0.73).

\section{Discussion}

The mean body weights of Horro chicken were generally within the ranges reported for unselected indigenous populations in northwestern Ethiopia (Halima et al. 2007) and many other countries of Africa (Gueye 1998). The average number of eggs as well as the rate of lay to 44 weeks of age was quite low. Comparative data on early part period egg production of other Ethiopian local chickens is not available. The peak production was attained in the fourth month of lay on the level of $32 \%$ ( 9 eggs/hen). The figures generally confirm previous reports showing that indigenous chickens of Ethiopia and of many other African countries are poor egg layers (Gueye 1998; Dana and Ogle 2002).

Body weights to 16 weeks of age were used to characterize the growth of chicken in this study. Selection for rapid early growth at a market age (40-50 days) has been the most common approach in broiler chicken breeding programs (Emmerson 2003). Our results showed that body weight at 16 weeks of age has a positive correlation to growth from 2 to 12 weeks of age. The correlations were particularly strong with certain growth traits $\left(r_{\mathrm{g}}=0.82\right.$ with $\mathrm{BW} 8$, and 0.99 with BW12). Body weight at 16 weeks was also relatively the most heritable among the other growth traits measured. Therefore, since chickens in Ethiopia are kept for both meat and egg production attaining mature body size at earlier ages is not the target of the production system, and thus, selection at 16 weeks of age could be the most suitable approach to improve growth.

Heritabilities of monthly egg productions decreased from 0.32 in month 1 to 0.25 at peak egg production in month 4 , except for month 3 which was exceptionally high $\left(h^{2}=0.56\right)$. A comparable pattern of heritability changes in monthly egg numbers has also been reported by Anang et al. (2002) and Wolc and Szwaczkowski (2009). Heritabilities of cumulative part period egg numbers $(0.24-0.35)$ were within the range 
reported by Sang et al. (2006) who found moderate values (0.24-0.37) in five Korean native chicken strains for total egg numbers from start to 270 days of lay and the figures (0.31-0.32) reported by Lwelamira et al. (2009) for cumulative number of eggs produced in the first 90 days of laying in indigenous Tanzanian chickens. Sabri et al. (1999) also reported heritabilities of $0.27,0.19$, and 0.30 for egg numbers produced between 26 and 30,50 and 54, and 26 and 54 weeks period, respectively, for White Leghorn hens in a subtropical environment. Higher values were reported by Anang et al. (2000) for cumulative egg production of the first 5 months in White Leghorn chickens $\left(h^{2}=0.46\right)$ and by Kamali et al. (2007) for the first 12 weeks of egg production $\left(h^{2}=0.49\right)$ in Iranian indigenous fowls compared to our results.

Part period egg numbers were relatively more heritable and consistent than monthly egg productions. Most of the monthly egg production traits were poorly related with each other and with cumulative egg production while the correlations among the latter traits remained quite high. Particularly, the total number of eggs produced to 44 weeks of age (EP3) was found to be the most heritable trait $\left(h^{2}=0.35\right)$ having a strong positive correlation with BW16 $\left(r_{\mathrm{g}}=0.73\right)$. These two traits seemed to have common genes and utilizing them as selection traits would be expected to improve both egg production and growth performance of local chicken. The standard errors of estimates in this study were mostly high indicating that the estimates have low precision and parameter estimations based on more data are needed before applying the current results in breeding programs.

However, the trends drawn from the phenotypic performances of growth and total egg production to 44 weeks of age showed that hens heavier at 16 weeks of age laid higher number of eggs where as the non-layers weighed less suggesting that body weight at 16 weeks of age could be a good indicator for egg production, which is in agreement with the high genetic correlation (0.69-0.92). Hens with the highest egg production ( $>70$ eggs at 44 weeks of age) comprised about $10 \%$ of the flock, and thus, might be considered as potential candidates for selection based on phenotypic performance (see Figs. 1 and 2). This can form the basis for selection instead of random picking for the following generation.

Selection based on early period part records, up to 40 weeks of age, could result in increased egg production of chickens (Fairful and Gowe 1990; Poggenpoel et al. 1996). Estimates for part records can be used as selection criteria to improve both part and annual egg production and any loss in accuracy is compensated by the reduction in generation interval, thus maximizing genetic gain per unit of time (Ayyagari et al. 1980). Hicks et al. (1998) also showed that selection based on partial records of the individual and all available ancestral records resulted in the shortest generation interval and was the most efficient strategy for maximizing egg production in laying hens compared to other strategies using full records. Various models have been proposed to predict annual egg production from early part record egg production (McMillan et al. 1986; Grossman and Koops 2001).

\section{Conclusions}

Growth and egg production are economically the most important traits in small holder poultry production systems. An earlier study in Ethiopia showed that farmers across all geographic regions rated them as the traits they wanted to be improved the most (Dana et al. 2010). Since chickens under rural production systems are kept both for meat and egg production selection for genetic improvement of local chickens should seek to improve the two traits simultaneously. This study revealed that body weight at 16 weeks of age has a strong genetic correlation with the total number of eggs recorded from housing to 44 weeks of age. These two traits also showed higher level of heritability, relative to their respective trait categories. However, the precision of estimates particularly on egg production traits is low due to the small number of records used. Therefore, further work is recommended to confirm the current results using larger number of records.

Acknowledgments We sincerely thank the farm attendants who worked on data collection at the poultry farm of Debre Zeit Agricultural Research Center. We also would like to sincerely thank Dr. Kibebew Asefa, Mr. Wondimeneh Esatu, and Mr. Alemayehu Amare for their support. This experiment is funded jointly by the Ethiopian Institute of Agricultural Research (EIAR) and The Netherlands Foundation for the Advancement of Tropical Research (WOTRO) grant number WB 89-178.

Open Access This article is distributed under the terms of the Creative Commons Attribution Noncommercial License which permits any noncommercial use, distribution, and reproduction in any medium, provided the original author(s) and source are credited.

\section{References}

Anang, A., Mielenz, N. and Schüler, L., 2000. Genetic and phenotypic parameters for monthly egg production in White Leghorn hens, Journal of Animal Breeding and Genetics, 117, 407-415

Anang, A., Mielenz, N. and Schüler, L., 2002. Monthly model for genetic evaluation of laying hens: II random regression, British Poultry Science, 43, 384-390

Ayyagari, V., Mohapatra, S.C., Venkatramaiah, A., Thiagasundaram, T., Choudhuri, D., Johri, D.C. and Renganathan, P., 1980. Selection for egg production on part records, Theoretical and Applied Genetics, 57, 277-283

Besbes, B., 2009. Genotype evaluation and breeding of poultry for performance under suboptimal village conditions, World's Poultry Science Journal, 65, 260-271 
Besbes, B., Ducrocq, V., Foulley, J-L., Protais, M., Tavernier, A., TixierBoichard, M. and Beaumont, C., 1993. Box-Cox transformation of egg production traits of laying hens to improve genetic parameter estimation and breeding evaluation, Livestock Production Science, 33, 313-326

Chambers, J.R., 1990. Genetics of growth and meat production in chickens. In: R.D. Crawford (ed), Poultry Breeding and Genetics, (Elsevier Science, Amsterdam), 599-644

Dana, N. and Ogle, B., 2002. Effects of scavenging on diet selection and performance of Rhode Island Red and Fayoumi breeds of chicken offered a choices of energy and protein feeds, Tropical Animal Health and Production, 34, 417-429

Dana, N., vander Waaij, L. H., Dessie, T. and van Arendonk, J.A.M., 2010. Production objectives and trait preferences of village poultry producers of Ethiopia: implications for designing breeding schemes utilizing indigenous chicken genetic resources, Tropical Animal Health and Production, doi:10.1007/s11250-010-9602-6

Emmerson, D., 2003. Breeding objectives and selection strategies for broiler production. In: W.M. Muir and S.E. Aggrey (eds), Poultry Breeding, Genetics and Biotechnology, (CAB International, UK), $113-126$

Fairful, R.W. and Gowe, R.S., 1990. Genetics of egg production in chickens. In: R.D. Crawford (ed), Poultry Breeding and Genetics, (Elsevier Science, Amsterdam), 705-760

Francesch, A., Estany, J., Alfonso, L. and Iglesias, M., 1997. Genetic parameters for egg number, egg weight, and eggshell colour in three Catalan poultry breeds, Poultry Science, 76, 1627-1631

Gilmour, A.R., Gogel, B. J., Cullis, B.R. and Thompson, R., 2006. ASReml User Guide, Release 2.0, (NSW Department of Primary Industries, Australia)

Gondwe, T.N.P., 2005. Characterization of local chicken in low inputlow output production systems: is there scope for appropriate production and breeding strategies in Malawi?, (unpublished $\mathrm{PhD}$ thesis, Georg-August-Universitat Gottingen)

Grossman, M. and Koops, W.J., 2001. A model for individual egg production in chickens, Poultry Science, 80, 859-867

Gueye, E.F., 1998. Village egg and fowl meat production in Africa, World's Poultry Science Journal, 54, 73-86

Halima, H., Neser, F.W.C., van Marle-Koster, E. and de Kock, A., 2007. Phenotypic variation of indigenous chicken populations in northwest Ethiopia, Tropical Animal Health and Production, 39, 507-513

Halima, H., Neser, F.W.C., de Kock, A. and van Marle-Koster, E., 2009. Study on the genetic diversity of native chickens in northwest Ethiopia using microsatellite markers, African Journal of Biotechnology, 8(7), 1347-1353

Hicks, C., Muir, W. M. and Stick, D. A., 1998. Selection index updating for maximizing rate of annual genetic gain in laying hens, Poultry Science, 77, 1-7

Horst, P., 1989. Native fowls as reservoir for genomes and major genes with direct and indirect effect on the adaptability and their potential for tropically oriented breeding plans, Archiv fur Geflugelkunde, 53 (3), 93-101

Kamali, M.A., Ghorbani, S.H., Moradi Sharbabak, M. and Zamiri, M.J., 2007. Heritabilities and genetic correlations of economic traits in Iranian native fowl and estimated genetic trend and inbreeding coefficients, British Poultry Science, 48(4), 443448

Lwelamira, J., Kifaro, G.C. and Gwakisa, P. S., 2009. Genetic parameters for body weights, egg traits and antibody response against Newcastle Disease Virus (NDV) vaccine among two Tanzania chicken ecotypes, Tropical Animal Health and Production, 41, 51-59

McMillan, I., Gowe, R.S., Gavora, J.S. and Fairfull, R.W., 1986. Prediction of annual production from part record egg production in chickens by three mathematical models, Poultry Science, 65 (5), 817-822

Muchadeyi, F.C., Eding, H., Wollny, C.B.A., Groeneveld, E., Makuza, S.M., Shamseldin, R., Simianer, H. and Weigend, S., 2007. Absence of population substructuring in Zimbabwe chicken ecotypes inferred using microsatellite analysis, Animal Genetics, 38, 332-339

Mwacharo, J.M., Nomura, K., Hanada, H., Jianlin, H., Hanotte, O. and Amano, T., 2007. Genetic relationships among Kenyan and other East African indigenous chickens, Animal Genetics, 38, $485-490$

Norris, D. and Ngambi, J.W., 2006. Genetic parameter estimates for body weight in local Venda chickens, Tropical Animal Health and Production, 38, 605-609

Poggenpoel, D.G., Ferreira, G.F., Hayes, J.P. and du Preez, J.J., 1996. Response to long-term selection for egg production in laying hens, British Poultry Science, 37(4), 743-756

Sabri, H.M., Wilson, H.R., Harms, R.H. and Wilcox, C.J., 1999. Genetic parameters for egg and related characteristics of white leghorn hens in a subtropical environment, Genetics and Molecular Biology, 22(2), 183-186

Sang, B., Kong, H.S., Kyukim, H., Choi, C.H., Kim, S.D., Cho, Y.M., Sang, B.C., Lee, J.H., Jeon, G.J. and Lee, H.K., 2006. Estimation of genetic parameters for economic traits in Korean native chickens, Asian-Australasian Journal of Animal Sciences, 19(3), 319-323

Statistical Analysis System (SAS), 2001. SAS Users' Guide, Version 9.1, (SAS Institute Inc, North Carolina)

Teklewold, H., Dadi, L., Yami, A. and Dana, N., 2006. Determinants of adoption of poultry technology: a double hurdle approach, Livestock Research for Rural Development, 18(3), (http://www. cipav.org.co/lrrd/1rrd18/3/tek118040.htm)

Wolc, A. and Szwaczkowski, T., 2009. Estimation of genetic parameters for monthly egg production in laying hens based on random regression models, Journal of Applied Genetics, 50(1), $41-46$ 